\title{
Combined Convection Heat Transfer to Thermally Developing Air Flow inside a Circular Inclined Cylinder
}

\author{
Yasin K. Salman \\ Professor \\ Energy Engineering Department \\ College of Engineering \\ University of Baghdad
}

\author{
Yasmeen Raad Saeed \\ Energy Engineering Department \\ College of Engineering \\ University of Baghdad
}

\begin{abstract}
Heat transfer by mixed convection to a hydro dynamically developed airflow from the inside surface of inclined circular cylinder subjected to a constant heat flux investigated experimentally. An experimental test rig has a test section with $500 \mathrm{~mm}$ length and $46 \mathrm{~mm}$ inside diameter aluminum cylinder $(\mathrm{L} / \mathrm{D}=10.87)$ proceeds with $1100 \mathrm{~mm}$ calming section having a Teflon bell mouth piece at its inlet to adopt a fully developed flow hydrodynamically at the test section inlet. The experiments covered Reynolds number ranged between 350 to 850 , heat flux varies between $100 \mathrm{w} / \mathrm{m}^{2}$ to 700 $\mathrm{w} / \mathrm{m}^{2}$ and cylinder orientation varies between $0^{\circ}$ (horizontal) to $90^{\circ}$ in the assistant mixed convection situations and $-20^{\circ}$ in the opposite mixed convection situation. The surface temperature distributions have general shape which increases with the increasing heat flux rate and decreasing Reynolds number. The local and average heat transfer coefficient results demonstrate that the local heat transfer coefficient represents the axial position at which can accept a fully developed flow thermally. The average heat transfer coefficient result of the horizontal tcylinder shows a reduction in heat transfer coefficient as heat flux increases. The results also show average Nusselt number variation with axial dimensionless distance $\mathrm{Z}^{+}$. For five angles of inclinations, correlation equations between average number and $\mathrm{ZZ}$ parameter have been delivered. Another five correlation equation between average Nusselt number and ZZq Parameter based on the modified Grashof Nussult number also have been introduced. A comparison with previous work shows an agreement in the heat transfer trends for the horizontal and inclined opposing mixed convection situations.
\end{abstract}

\section{Keywords}

Heat Transfer, Mixed convection, Thermally developing flow, Inclined cylinder.

\section{INTRODUCTION}

Combination of natural and forced convection, also known as mixed convection, happens when natural and forced convections mechanisms used together to get rid of high temperature. This is general, combined convection, can be distinguished in one of three ways depending on the interaction between the directions of forced convection flow in relation direction of natural convection flow. The first instance is when natural convection and forced convection works in the same direction and they are aiding each other. The second instance is when natural and forced convection works in the opposite directions of each other. The third instance called transverse flow. This happens when the buoyant motion acts perpendicular to the thrust move. This enhances fluid mixing, and raises the heat transfer. Mixed convection in cylinders has many industrial engineering applications that often regarded in very-high-power-output devices where the forced convection is not enough to disperse all of the heat necessary. At this period, combining natural convection with forced convection will often render the wanted outcomes. Instances of these processes are nuclear reactor engineering and in heating or cooling of heat exchangers for viscous liquids, heat exchangers for gas flows, electronic cooling, compact heat exchangers, and the cooling of rotating parts such as rotor blades of gas turbine also the pipe lines used for transporting oil. Raisee and Shahraeeni [1], (2007), made numerical simulation on vertical tubes that uniformly heated with laminar mixed convection air flow. For a bit of heating lengths, the Navier-Stokes and energy equations were solved using a finite-volume code which solves the governing equations in axisymmetric coordinate system, with Reynolds number $\mathrm{Re}=500$ which depends on the fluid bulk velocity and diameter of the pipe, and Grashof number $\mathrm{Gr}=10^{6}$ which depends on wall heat flux.it was resolved that the velocity near the wall increases for the buoyancy-aided convection, and decreases in the center area. These outcomes in an enhancement of wall heat transfer coefficient. Ozsunar et-al [2], (2001), investigated experimentally mixed convection heat transfer in rectangular channels. The lower surface of the channel is subjected to a uniform heat flux; side walls are insulated and adiabatic, while the upper surface is exposed to the surrounding fluid. Experiments were set up for $\mathrm{pr}=0.7$, aspect ratios $\mathrm{AR}=5$ and 10 , inclination angles $0^{0} \leq \Theta \leq 30^{\circ}$, Reynolds numbers $50 \leq$ $\mathrm{Re} \leq 1000$, and modified Grashof numbers $\mathrm{Gr}^{*}=7.0 \times 10^{5}$ to $4.0 \times 10^{7}$. From this experimentation, the effect of channel inclination and the local Nusselt number distributions were obtained, surface heat flux, and Reynolds number on the onset of instability were investigated. Mohammed and Yusaf [3], (2006), studied the effect of the flow pattern on the mixed convection heat transfer in circular tube with uniform wall heat input axially. The test fluid was air. . On a $900 \mathrm{~mm}$ copper tube a 28 thermocouple wire was used to measure the dispersion of the temperature. The range of Reynolds number from 410 to 1600 and heat flux varied from $63 \mathrm{~W} / \mathrm{m}^{2}$ to $1260 \mathrm{~W} / \mathrm{m}^{2}$, with different angles of tube inclination of $30^{\circ}$, $45^{\circ}, 60^{\circ}$, and 90 . It was found that the variance of the surface temperature along the tube for opposing flow higher than the assisted flow but more down than the horizontal orientation. The Reynolds number has a significant consequence on the Nusselt number in the opposing flow while the effect was found to be low in the case of assisted flow. Mohammed and Salman [4], (2006), studied experimentally a combined (free and forced) convection of the hydro-dynamically fully developed local and average heat transfer, which is thermally developing and thermally fully developed laminar air flow in a horizontal circular cylinder. The experimental setup consists of an aluminum cylinder as test section with $30 \mathrm{~mm}$ inside 
diameter and $900 \mathrm{~mm}$ heated length $(\mathrm{L} / \mathrm{D}=30)$, is subjected to a constant wall heat flux boundary condition. The study covers a Reynolds number ranges from 400 to 1600 , the heat flux varied from $60 \mathrm{~W} / \mathrm{m}^{2}$ to $400 \mathrm{~W} / \mathrm{m}^{2}$ and with the cylinder inclination angle of $\mathrm{h}=0^{\circ}$ (horizontal). The entrance sections included two long, calming sections, one with a length of 180 $\mathrm{cm}(\mathrm{L} / \mathrm{D}=60)$, another one with a length of $240 \mathrm{~cm}(\mathrm{~L} / \mathrm{D}=$ $80)$ and two short calming sections with length $60 \mathrm{~cm}(\mathrm{~L} / \mathrm{D}=$ $20), 120 \mathrm{~cm}(\mathrm{~L} / \mathrm{D}=40)$. In all entrance sections, it found an increase in the Nusselt number values as the heat flux increases. It was reasoned that the free convection effects tended to diminish the heat transfer results at low Re while to increase the heat transfer results for high Re. Dogan et-al [5], (2006), with arrays of discrete heat sources studied experimentally mixed convection heat transfer within the horizontal channel. With insulated and adiabatic sides, upper and lower walls, from the experimental measurements, rowaverage surface temperature and Nusselt number distributions of the discrete heat sources were obtained and effects of Reynolds and Grashof numbers of these numbers were looked into. The answers establish that top and bottom heater surface temperatures increase with the increasing Grashof number. For high values of Grashof numbers where natural convection is the dominant heat transfer regime $(\mathrm{Gr} * / \operatorname{Re} 2 \gg 1)$, temperatures of top heaters can deliver much larger value. Mare et-al [6], (2005), Laminar mixed convection in isothermal tubes has been studied numerically and experimentally The present work considers the three dimensional developing laminar flow of water with constant viscosity and conductivity in an isothermal pipe inclined of $60^{\circ}$ from horizontal. At the beginning, the elliptic partial differential equations modeling, mixed convection, have been numerically solved using a control volume based finite difference solver for $\operatorname{Re}=90, \operatorname{Pr}=7$ and $\mathrm{Gr}=3.3 \times 10^{5}$. Secondly, an experimental setup is identified. The techniques employed are almost the same based on PIV technology employing micrometer Nylon particles placed in a laser lightsheet and solutions are recorded by using a CDD camera. Analyzed pictures have confirmed the existence of the reverse flow region in accordance with mathematical results as obtained for an inclination of $60^{\circ}$.

\section{EXPERIMENTAL APPARATUS AND PROCEDURE}

\subsection{Description of Apparatus}

The experimental setup of the system is shown as schematically with the cross-sectional details of the test section demonstrate in figure 1 . The open loop system consists of three parts; inlet calming section, test section and outlet section. The inlet calming section (B) consists of aluminum cylinder with $46 \mathrm{~mm}$ inside diameter, $50 \mathrm{~mm}$ outside diameter, $1200 \mathrm{~mm}$ long ( $\mathrm{L}_{\text {int }} / \mathrm{D}$ equal to 26.1 ) and with a Teflon bell mouth (A) at the calming section entrance. The calming section uses to wipe out the fluctuations and achieve steady fully developed hydrodynamically flow at the test section entrance. The test section (D) is an aluminum cylinder with $46 \mathrm{~mm}$ inside diameter, $50 \mathrm{~mm}$ outside diameter and $500 \mathrm{~mm}$ long $(\mathrm{L} / \mathrm{D}=10.87)$. A Teflon piece $(\mathrm{C})$ is fitted at the test section cylinder entrance, and a same Teflon piece (C) is fitted at the test section exit. Two Teflon pieces are machined with an inside diameter exactly as the calming and test section cylinders inside diameters. The air then leaves the test section via a flexible tube (L) in which a stop valve installed to adjust the air flow rate. A rotameter $(F)$ is used to measure the air flow rate. The air then leaving the open air loop via the centrifugal fan $(\mathrm{G})$. All thermocouples leads $(\mathrm{H})$ connect to the selector switch (I) contains 16 thumb wheels to convert the thermocouples signal to the data logger $(\mathrm{J})$. The digital signal of the thermocouples converts by data logger which was controlled and set by special soft wear runs by the lab top $(\mathrm{K})$. The inclination of the test section was controlled by firmly fixing and aligning both calming and test sections on a rotating wooden board and that allowing rotating the test rig from horizontal to vertical.

The details of the test section also are shown In Fig. (1). The main heating element (2) for the aluminum cylinder is an electrically heated nickel-chromium wire having a $0.3 \mathrm{~mm}$ outer diameter; Ceramic beads are used for isolate the main heater electrically. Two asbestos insulation layers (3) of 30 $\mathrm{mm}$ total thickness wrapped covering the main heater. Then three sets of pairs of thermocouples (A1/A2, B1/B2, and $\mathrm{C} 1 / \mathrm{C} 2$ ) attached on two aluminum strips separated by $10 \mathrm{~mm}$ asbestos insulation (4) wrapped over the first insulation layer (3). Another $10 \mathrm{~mm}$ thick asbestos layer (5) covers the previous layers. The guard heater (6) wound around the entire length of the test section cylinder in a uniform manner. Another $10 \mathrm{~mm}$ thick of asbestos layer (7) is used to cover the guard heater. The last shield for heating system, a layer of fiber glass (8) of $7 \mathrm{~mm}$ thickness is used lastly.

The axial temperature distribution of the tested cylinder inside surface was accomplished by using 17 Type K (chromel alumel) thermocouples of $0.276 \mathrm{~mm}$ in size and the location along the tested cylinder. The temperature distribution measurement around the test section cylinder circumference was accomplished by installing three additional thermocouples around the outer surface of the test section 250 $\mathrm{mm}$ from the test section entrance, spaced 90 angle degree. One thermocouple was positioned at the Teflon piece (C) of the test section cylinder entrance to measure the air inlet temperature and three thermocouples are fixed at the test section cylinder outlet spaced circumferentially $120^{\circ}$ angle to measure the air outlet (bulk air) temperature.

\subsection{Experimental Procedure}

The test runs started in June 2017and in October 2017. This period covers 80 test runs involving 16 test runs for the five cylinder orientations, $0^{\circ}$ (horizontal), $30^{\circ}, 60^{\circ}, 90^{\circ}$ (assisting or aiding flow)and $-20^{\circ}$ (opposing flow). Below is the procedure that was followed during experimental part of the project:

1. The test apparatus prepared to ensure high performance of all system components.

2. Angle of inclination was controlled and adjusted by rotating the horizontal spindle located below the platform.

3. The supply power to the electric heaters and the electric axial fan were switched on, and they were adjusted by variac to obtain the required constant heat flux and the required Reynolds number. The value of the voltage and current was indicated by the digital voltmeter and the ammeter.

4. The guard heater was powered on, voltage andcurrent were recorded.

5. Using the data logger the reading of the thermocouples was recorded for each half hour and the guard heater voltage adjusted and controlled accordingly so that each pair of the guard heater thermocouples would acquire the same temperature. To reach the steady state condition, a period of (2-3) 
hours is required. Then the following reading was recorded:

a. Inclination angle of the circular cylinder in Degrees.

b. The test section cylinder surface temperatures.

c. The voltage and the current for the test section cylinder main heater and guard heater.

d. The required Reynold number and the reading of flow meter.

e. The temperature of the air at the test section cylinder inlet and outlet.

f. The ambient temperature.

6. The input power to the heaters and fan were then changed and a new experiment started.

\subsection{Experimental Data analysis}

The cylinder surface was subjected to the uniform heat flux. The total power supplied to the cylinder was calculated as follows:

$\mathrm{Q}_{\mathrm{t}}=\mathrm{V} \times \mathrm{I}$

The convection and radiation heat transferred from the cylinder inner surface is calculated as follow:

$\mathrm{Qcr}=\mathrm{Qt}-\mathrm{Qcond}$

Where: Qcond represents the axial conduction heat loss which was found experimentally equal to $3 \%$ of the total input power. The convection and radiation heat flux can be represented by:

$\mathrm{qcr}=\mathrm{Qcr} / \mathrm{As}=\mathrm{qc}+\mathrm{qr}$

Where As $=\pi \mathrm{DL}$

The convection heat flux qc which is used to calculate the local heat transfer coefficient is obtained after deducing the radiation heat flux qr from qcr value. The local radiation heat flux qr can be evaluated as follow

$$
\mathrm{q}_{\mathrm{r}}=\mathrm{F}_{1-1} \sigma \varepsilon\left(\left(\mathrm{T}_{\mathrm{s}}+273\right)^{4}-\left(\mathrm{T}_{\mathrm{s}, \mathrm{L}}+273\right)^{4}\right)(5)
$$

where: $\mathrm{F}_{1-1} \approx 1$ the radiative heat flux is very small as the temperature difference between the local surface temperature $\mathrm{Ts}, \mathrm{X}$ and the average surface temperature Ts,L for cylinder inner surface was found very small and approximately equal $5 \%$ total heat flux qcr. Hence the convection heat flux at any position I

$\mathrm{q}_{\mathrm{c}}=\mathrm{q}_{\mathrm{cr}} \times 0.95$

The local heat transfer coefficient $\mathrm{hx}$ can be obtained

$$
\text { as } \quad \mathrm{h}_{\mathrm{x}}=\frac{\mathrm{q}_{\mathrm{c}}}{\left(\mathrm{T}_{\mathrm{s}, \mathrm{x}}-\mathrm{T}_{\mathrm{b}, \mathrm{x}}\right)}
$$

Where: Ts,x represents local surface temperature whileTb,x represents the local bulk air temperature. All the air properties were evaluated at the mean film air temperature:

$\mathrm{T}_{\mathrm{f}, \mathrm{x}}=\frac{\left(\mathrm{T}_{\mathrm{s}, \mathrm{x}}-\mathrm{T}_{\mathrm{b}, \mathrm{x}}\right)}{2}$

Where: $T_{f, x}$ represents the local mean film air temperature at $x$ position .The average surface temperature $T_{s, L}$, average bulk air temperature $\mathrm{Tb}, \mathrm{L}$ and the average film air temperature for specific cylinder length $L$ evaluated as:

$$
\mathrm{T}_{\mathrm{S}, \mathrm{L}}=\frac{1}{\mathrm{~L}} \int_{\mathrm{X}=0}^{\mathrm{x}=\mathrm{L}} \mathrm{T}_{\mathrm{S}, \mathrm{X}} \mathrm{dx}
$$

$$
\begin{gathered}
\mathrm{T}_{\mathrm{b}, \mathrm{L}}=\frac{1}{\mathrm{~L}} \int_{\mathrm{x}=0}^{\mathrm{x}=\mathrm{L}} \mathrm{T}_{\mathrm{b}, \mathrm{x}} \mathrm{dx} \\
\mathrm{T}_{\mathrm{f}, \mathrm{L}}=\frac{\left(\mathrm{T}_{\mathrm{s}, \mathrm{L}}-\mathrm{T}_{\mathrm{b}, \mathrm{L}}\right)}{2}
\end{gathered}
$$

The average heat transfer coefficient $\mathrm{hL}$ can be obtained as

$$
\mathrm{h}_{\mathrm{L}}=\frac{1}{\mathrm{~L}} \int_{\mathrm{x}=0}^{\mathrm{x}=\mathrm{L}} \mathrm{h}_{\mathrm{x}} \mathrm{dx}
$$

The local dimensionless groups $\mathrm{NuD}, \mathrm{x}, \mathrm{ReD}, \mathrm{x}, \mathrm{GrD}, \mathrm{x}$, and $\mathrm{RaD}, \mathrm{x}$ calculated as follow:

$$
\begin{aligned}
\mathrm{Nu}_{\mathrm{D}, \mathrm{x}} & =\frac{\mathrm{h}_{\mathrm{x}} \cdot \mathrm{D}}{\mathrm{k}_{\mathrm{x}}} \\
\mathrm{Re}_{\mathrm{D}, \mathrm{x}} & =\frac{\mathrm{U} \cdot \mathrm{D}}{\mathrm{v}_{\mathrm{x}}} \\
\mathrm{Gr}_{\mathrm{D}, \mathrm{x}} & =\frac{\mathrm{g} \beta_{\mathrm{x}}\left(\mathrm{T}_{\mathrm{s}, \mathrm{x}}-\mathrm{T}_{\mathrm{b}, \mathrm{x}}\right) \cdot \mathrm{D}^{3}}{\mathrm{v}_{\mathrm{x}}^{2}} \\
\mathrm{Ra}_{\mathrm{D}, \mathrm{x}} & =\mathrm{Gr}_{\mathrm{D}, \mathrm{x}} \operatorname{Pr}_{\mathrm{x}}
\end{aligned}
$$

Where Prx represents the Prandtl number $\left(\frac{\mu \cdot C_{p}}{k}\right)$ evaluated at local film temperature Tf, $\mathrm{x}$ and $\beta_{\mathrm{x}}=\frac{1}{\left(273+\mathrm{T}_{\mathrm{f}, \mathrm{x}}\right)}$

The average dimensionless groups $\mathrm{NuD}, \mathrm{L}, \mathrm{ReD}, \mathrm{L}, \mathrm{GrD}, \mathrm{L}$, and $\mathrm{RaD}, \mathrm{L}$ calculated as follow:

$$
\begin{aligned}
& \mathrm{Nu}_{\mathrm{D}, \mathrm{L}}=\frac{\mathrm{h}_{\mathrm{L}} \cdot \mathrm{D}}{\mathrm{k}_{\mathrm{L}}} \\
& \mathrm{Re}_{\mathrm{D}, \mathrm{L}}=\frac{\mathrm{U} \cdot \mathrm{D}}{\mathrm{v}_{\mathrm{L}}} \\
& \mathrm{Gr}_{\mathrm{D}, \mathrm{L}}=\frac{\mathrm{g} \beta_{\mathrm{L}}\left(\mathrm{T}_{\mathrm{s}, \mathrm{L}}-\mathrm{T}_{\mathrm{b}, \mathrm{L}}\right) \cdot \mathrm{D}^{3}}{\mathrm{v}_{\mathrm{L}}^{2}} \\
& \mathrm{Ra}_{\mathrm{D}, \mathrm{L}}=\mathrm{Gr}_{\mathrm{D}, \mathrm{L}} \operatorname{Pr}_{\mathrm{L}}
\end{aligned}
$$

Where PrL represents the Pradtle number $\left(\frac{\mu \cdot C_{p}}{k}\right)$ evaluated at average film temperature Tf,L and Where $\beta_{\mathrm{L}}=\frac{1}{\left(273+\mathrm{T}_{\mathrm{fL}}\right)}$

The modified dimensionless group $\mathrm{GrD}, \mathrm{x}^{*}, \mathrm{GrD}, \mathrm{L}^{*}, \mathrm{RaD}, \mathrm{x}^{*}$ and $\mathrm{RaD}, \mathrm{L}^{*}$ calculated as:

$$
\begin{gathered}
\mathrm{Gr}_{\mathrm{D}, \mathrm{x}}^{*}=\mathrm{Gr}_{\mathrm{D}, \mathrm{x}} \cdot \mathrm{Nu}_{\mathrm{D}, \mathrm{x}}=\frac{\mathrm{g} \beta_{\mathrm{x}} \mathrm{qD} \mathrm{D}^{4}}{\mathrm{k}_{\mathrm{x}} \cdot \mathrm{v}_{\mathrm{x}}^{2}} \\
\mathrm{Gr}_{\mathrm{D}, \mathrm{L}}^{*}=\mathrm{Gr}_{\mathrm{D}, \mathrm{L}} \cdot \mathrm{Nu}_{\mathrm{D}, \mathrm{L}}=\frac{\mathrm{g} \beta_{\mathrm{L}} \mathrm{q} \mathrm{D}}{\mathrm{k}_{\mathrm{L}} \cdot \mathrm{v}_{\mathrm{L}}^{2}} \\
\mathrm{Ra}_{\mathrm{D}, \mathrm{x}}^{*}=\mathrm{Gr}_{\mathrm{D}, \mathrm{x}}^{*} \operatorname{Pr}_{\mathrm{x}} \\
\mathrm{Ra}_{\mathrm{D}, \mathrm{L}}^{*}=\mathrm{Gr}_{\mathrm{D}, \mathrm{L}}^{*} \operatorname{Pr}_{\mathrm{L}}
\end{gathered}
$$

The dimensionless axial distance $\mathrm{Z}+$ presented by the following expression:

$$
\mathrm{Z}^{+}=\frac{\mathrm{X}}{\mathrm{D} \cdot \mathrm{Re}_{\mathrm{D}, \mathrm{L}} \cdot \operatorname{Pr}_{\mathrm{L}}}
$$

The correlation will be presented between average Nusselt number NuD,L and either the parameter ZZ (based on average Grashof umber GrD,L) or the parameter $\mathrm{ZZq}$ ( based on average Grashof number GrD, $\mathrm{L}^{*}$ ). These parameters $\mathrm{ZZ}$ and ZZq Will be used to include both natural and forced convection effecting dimensionless parameters Grashof number and Reynolds number.

$$
\begin{aligned}
\mathrm{ZZ} & =\frac{\mathrm{L} \cdot \mathrm{Ra}_{\mathrm{D}, \mathrm{L}}}{\mathrm{D} \cdot \mathrm{Re}_{\mathrm{D}, \mathrm{L}} \cdot \mathrm{Pr}_{\mathrm{L}}} \\
\mathrm{ZZ} & =\frac{\mathrm{L} \cdot \mathrm{Ra}_{\mathrm{D}, \mathrm{L}}^{*}}{\mathrm{D} \cdot \mathrm{Re}_{\mathrm{D}, \mathrm{L}} \cdot \mathrm{Pr}_{\mathrm{L}}}
\end{aligned}
$$


All the air physical properties $\rho, \mu, \mathrm{v}, \mathrm{Cp}$ and $\mathrm{k}$ were evaluated at the mean film temperature $\mathrm{Tf}$ Holman (2010) [7].

An algorithm was written FORTRAN computer language in order manipulates and analyzes the experimental data. The computer program capable to evaluate all air properties depending on polynomial type equations calculated in a very high accuracy. The best curve fitting polynomial degree for the local surface temperature and the local heat transfer coefficient selects automatically by a special criterion impeded in subroutine using least square method. The average surface temperature and average heat transfer coefficient for different cylinder length are integrated using a numerical integration subroutine which uses the local temperature and local heat transfer least square equations.

\subsection{Experimental Uncertainty}

Uncertainty or deviations may be due to several reasons when it comes to experimental measurements. This uncertainty may vary a great deal depending on the circumstances governing the experiment. . In the present work, the uncertainties in heat transfer coefficient (Nusselt number), Reynolds number and Rayleigh number were estimated based on the Kline and McClintock differential approximation method reported by Holman (2011)[8]. For a typical experiment, the total uncertainty in measuring the Surface to bulk air temperature, Voltage of the heater, Current of the heater, Diameter, Average lagging surface temperature and the flow of rotometer were $0.16 \%, 0.04 \%, 0.0003 \%, 0.0002 \%, 0.11 \%$, and $0.04 \%$ respectively. These were combined to give a maximum error of $2.57 \%$ in heat transfer coefficient (Nusselt number), maximum error of $2.36 \%$ in Rayleigh number, and maximum error of $0.05 \%$ in Reynold number

\section{RESULTS AND DISCUSSION}

In general, the surface temperature distribution Ts increases rapidly at cylinder entrance, but with decreasing gradient as the flow advanced along the cylinder axial distance to achieve a maximum value of approximately $(x=20 \mathrm{~cm})$ beyond which the distribution remains approximately constant for the remainder of the pipe length. The variation of local surface temperature along the horizontal cylinder, for different heat flux and for a constant Reynolds number $\operatorname{Re}_{\mathrm{D}}=850$ is shown in Fig. (3). The cylinder surface temperature has an obvious change with the cylinder axial distance at the cylinder entrance to be approximately constant for the rest of the cylinder with a small reduction at the cylinder exit due to the conduction end losses. The natural convection secondary flow in the horizontal cylinder is recirculating in a normal direction related to primary forced convection axial flow and the primary flow may be capable of drifting the natural convection secondary flow recirculating it in downstream creating a longitudinal vortex.

Fig. (4) shows the variation of local surface temperature along the horizontal cylinder, for different Reynolds numbers and for constant heat flux $q=700 \mathrm{~W} / \mathrm{m}^{2}$. In this figure the local surface temperature distribution $\mathrm{T}_{\mathrm{s}}$ demonstrated that for fixed heat flux the temperature distribution increases with the decreasing of Reynold number $\mathrm{Re}_{\mathrm{D}}$ the oscillation of the local temperature distribution is clearer than demonstrated in the previous figure which attributed to the natural convection secondary flow superimposed on the primary forced convection flow and that creating a longitudinal vortex along the cylinder inner surface improving the heat transfer process in the cylinder downstream region.
The effect of cylinder angle of inclination on the variation of local surface temperature along the cylinder for Reynolds number $\mathrm{Re}_{\mathrm{D}}=850$ and for surface heat flux $\mathrm{q}=700 \mathrm{~W} / \mathrm{m}^{2}$ is shown in Fig. (5). The local surface temperature distribution variation along the cylinder axis shows a lowest temperature for inclination angles $\left(\Theta=60^{\circ}\right)$, while the temperature distribution for the inclination angles $\left(90^{\circ}\right.$, and $\left.0^{\circ}\right)$ have highest temperature distributions in the figure. It can be seen from this figure that for all inclination angles the local surface temperature begins with low values at the entrance of the cylinder and then increasing with a reduced gradient along the axial position along the cylinder until reaching a maximum value then continue oscillating around a constant value.

Fig. (6) shows the variation of the average heat transfer coefficient for horizontal cylinder. The variation shows a sharp drop in the coefficient value till a specific axial length at which the coefficient value improving at the cylinder exit. As the horizontal orientation is a critical orientation for mixed convection falling between assisting mixed convection and opposed mixed convection and secondary natural convection expected to be normal to the primary forced convection flow, the results show a reduction in the heat transfer coefficient as the heat flux increasing for the parameter tested. Therefore, natural convection plays an obstacle in the heat transfer process and its effect increasing with increasing the cylinder surface heat flux.

The variation of mixed convection average heat transfer coefficient $\left(h_{L}\right)$ along cylinder five orientation, horizontal $(\theta$ $\left.=0^{\circ}\right)$, inclined aiding the flow $\left(\theta=30^{\circ}\right),\left(\theta=60^{\circ}\right)$, vertical and inclined opposed flow $\left(\theta=-20^{\circ}\right)$ are presented in Fig. (7). The result for the average heat transfer coefficient shown in figure reveals clearly that the inclination $\left(\theta=60^{\circ}\right)$ has the highest coefficient while the lowest results recorded for $\left(\theta=0^{\circ}\right)$ and $\left(\theta=-20^{\circ}\right)$.

Fig. (8) has been selected to show the variation of average Nusselt number with dimensionless axial distance $\mathrm{Z}^{+}$for horizontal cylinder, for different cylinder heat flux and for constant Reynolds number $\operatorname{Re}_{\mathrm{D}}=850$. The comparison between experimental results with analytical result of pure forced convection [9] reveals that the mixed convection heat transfer process deviation from relay on the assumption that the process is forced convection is quite clear. The analytical solution, average Nusselt number $\mathrm{Nu}_{\mathrm{D}, \mathrm{L}}$, for laminar forced convection heat transfer with a hydrodynamicall developed thermally developing flow in a circular cylinder subjected to a constant rate of heat flux, should go asymptotically with $\mathrm{Z}^{+}$at an average Nusselt number equal to 4.364 . For experiment mixed convection, the variation of average Nusselt number starts with a high value at the test section entrance, then a sharp fall to achieve a specific axial position upstream with a minimum average Nussult number after that an improvement in the average Nusselt number occurs to deviate from a pure forced convection value. The difference between mixed convection and pure forced convection in the average Nusselt number, which has occurred as the result of natural convection interference as secondary flow on the primary forced convection flow, increases downstream of the teat section.

For horizontal cylinder, at cylinder entrance the $\mathrm{Nu}_{\mathrm{D}, \mathrm{L}}$ has a large value due to small thickness of thermal boundary layers which begins to grow with the decreasing of $\mathrm{Nu}_{\mathrm{D}, \mathrm{L}}$, and then the value of $\mathrm{Nu}_{\mathrm{D}, \mathrm{L}}$ increases due to difference reduction between the average surface temperature $T_{s, L}$ and the average bulk air temperature $\mathrm{T}_{\mathrm{b}, \mathrm{L}}$. 
The effect of cylinder inclination angle on the average Nusselt number $\mathrm{Nu}_{\mathrm{D}, \mathrm{L}}$ with axial dimensionless position $\mathrm{Z}^{+}$for constant heat flux $=700 \mathrm{~W} / \mathrm{m}^{2}$ and constant values of Re number $\operatorname{Re}_{D}=850$ is shown in Fig. (9). It can be seen from figure that the values of average $\mathrm{Nu}_{\mathrm{D}, \mathrm{L}}$ number for inclined cylinder $\theta=60^{\circ}$ and inclined cylinder $\theta=30^{\circ}$ are higher than horizontal cylinder and other inclination angles. Due to inclination effect which expected to create a three dimensional flow generating a longitudinal vortex, the heat transfer coefficient results improve in comparison with horizontal cylinder and gives higher $\mathrm{Nu}_{D, L}$ value especially for inclination $\theta=60^{\circ}$. In the inclined assisting flow, for the same heat flux and same Reynold number the local surface temperature for $\left(\theta=60^{\circ}\right)$ is the lowest in comparison with other cylinder orientation. Therefore, the $\mathrm{Nu}_{\mathrm{D}, \mathrm{L}}$ results for $\theta=$ $60^{\circ}$ are the highest result for the all orientations tested. Whereas the horizontal orientation makes the forces of free and forced convection perpendicular to each other resulting in the loss of rotational symmetry and the effect of secondary flow is high. For opposed flow $(\theta=-20)$, The results demonstrated in this figure is a similar trend to that obtain for the horizontal cylinder as the $\mathrm{Nu}_{\mathrm{D}, \mathrm{L}}$ decreases as the surface heat flux increasing and the secondary natural convection flow not only restricted the primary forced convection flow, but also expected to create a recirculation bubble which dominates the upper part of the cylinder heat transfer process and diverting the primary forced convection flow to the lower part of the cylinder.

The experimental results were correlated for mixed convection of average Nusselt number $\mathrm{Nu}_{D, L}$ values with the dimensionless parameter $\mathrm{ZZ}^{+}$for five inclination angles $\theta$ equal to $0^{\circ}$ (horizontal) $, 30^{\circ}, 60^{\circ}$ (aiding flow), $90^{\circ}$ (vertical) and $-20^{\circ}$ (opposed flow) and with the dimensionless parameter $\mathrm{ZZ}_{\mathrm{q}}^{+}$(modified $\mathrm{ZZ}^{+}$based of the heat flux $\mathrm{q}$ ) also for five inclination angles These correlations are depicted on log-log scale with the average for whole cylinder length and for 16 test runs for each inclination angle. Mixed convection correlations for $\mathrm{NuD}, \mathrm{L}$ with parameter $\mathrm{ZZ}+$ are presented in following relation:

$$
\mathrm{Nu}_{\mathrm{L}, \mathrm{D}}=\mathrm{C}\left(\mathrm{ZZ}^{+}\right)^{\mathrm{m}}
$$

While mixed convection correlations for $\mathrm{NuD}, \mathrm{L}$ with parameter $\mathrm{ZZ}+\mathrm{q}$ are presented in following relation:

$$
\mathrm{Nu}_{\mathrm{L}, \mathrm{D}}=\mathrm{C}_{\mathrm{q}}\left(\mathrm{ZZ}_{\mathrm{q}}^{+}\right)^{\mathrm{m}_{\mathrm{q}}}
$$

The mixed convection heat transfer correlation constants $\mathrm{C}$, $\mathrm{m}, \mathrm{Cq}$ and $\mathrm{mq}$ for the above relations, for the five inclination angles are presented in the equation form in table (1).

Fig. (10-12) present the best and lowest cases of reduction in heat transfer process which are also shown in table (2) as the percentage improvement or reduction in heat transfer process in comparison with the critical case of horizontal cylinder mixed convection correlation.

\section{CONCLUSIONS}

1. The temperature variation has a general shape in which increased with gradual reduction rate till maximum value the oscillating at cylinder downstream. The oscillation around approximately constant temperature along the cylinder downstream with a diversion from pure forced convection and that can be attributes to natural convection superimposed.

2. For the same Reynold number distribution behavior gives evidence on the interference of natural convection in a longitudinal vortices form on the forced convection and heat flux, the surface temperature reduces when cylinder orientation moves from horizontal to inclined aiding flow while surface temperature remains constant or may be increases slightly as the cylinder moves from horizontal to inclined opposing flow which attribute to free convection dominating the circular cylinder upper part by recirculation bubble.

3. For aiding flow, as the heat flux increases heat transfer process improves at the same angle of inclination, while for horizontal and opposing flow, increasing heat flux come with a slight reduction in heat transfer process

4. For horizontal cylinder and for high heat flux, the average heat transfer coefficient decreases with increasing Reynolds number.

5. Heat transfer process improving as the cylinder moves from horizontal to vertical and for same heat flux and same Reynolds number the inclination angle $\left(\theta=60^{\circ}\right)$ gives the highest heat transfer performance.

6. The average Nusselt number $\mathrm{Nu}_{\mathrm{D}, \mathrm{L}}$ increases as heat flux increases and Re number increases

7. The higher value of average $\mathrm{Nu}$ number occurs at $\theta=60^{\circ}$ for high $\operatorname{Re}$ number when the super imposed natural convection on the forced convection works tremendously to improve the heat transfer process especially at the cylinder downstream.

8. Empirical correlations have been derived to evaluate the average Nusselt number $\mathrm{Nu}_{\mathrm{D}, \mathrm{L}}$ with $\mathrm{ZZ}$ parameter and with $\mathrm{ZZ}_{\mathrm{q}}$ parameter based on modified Grashof number $\mathrm{Gr}_{\mathrm{D}, \mathrm{L}}{ }^{*}$.

9. The present experimental results have been compared with the available literature for the horizontal and opposing flow and showed satisfactory agreement in trends

\section{ACKNOWLEDGMENTS}

The author gratefully acknowledges the financial support for this study received from the Energy Department, College of Engineering, University of Baghdad 


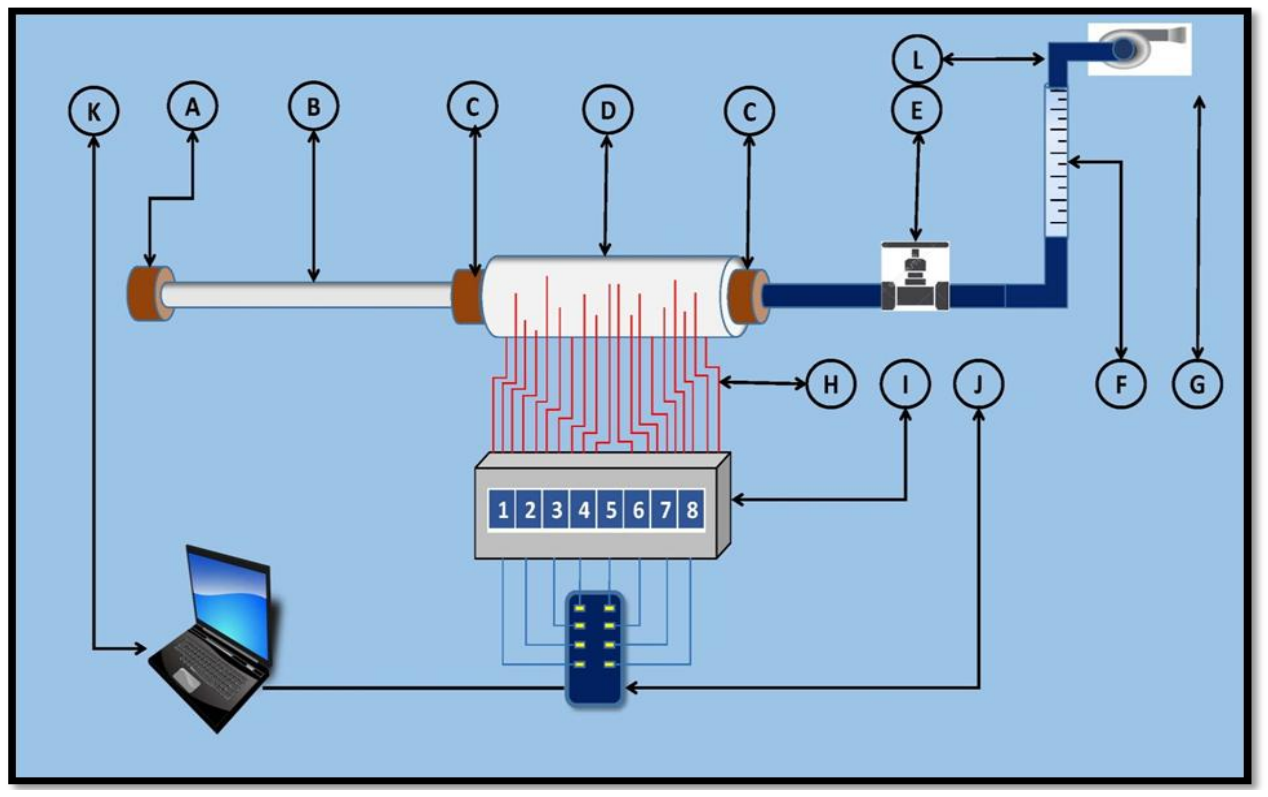

Fig. (1) Schematic diagram of experimental apparatus:(A) Bellmouth Teflon piece; (B) Calming section; (C) Teflon piece at the entrance and exit of the test section cylinder; (D) Test section; (E) Control valve; (F) Rotometer; (G) Centrifugal fan; (H) thermocouples leads (I) Selector switch; (J) Data logger; (K) Labtop; (L) Flexible tube.

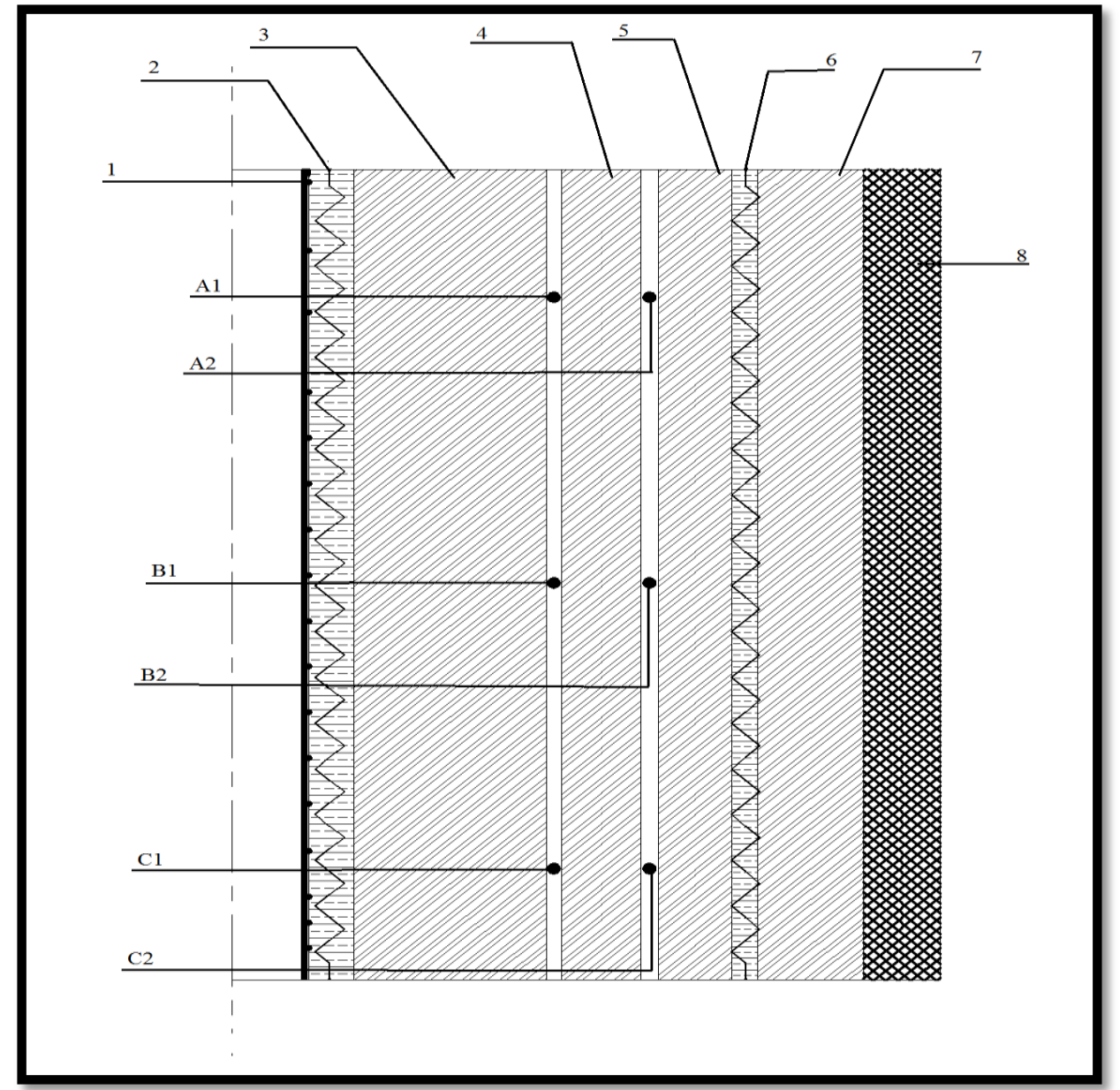

Fig (2) Cross-sectional Details of the apparatus test section.(1) cylinder with thermocouples ; (2) cylinder main heater with 5 mm (thickness) asbestos rope; (3) $30 \mathrm{~mm}$ (thickness) asbestos layer; (4) $10 \mathrm{~mm}$ asbestos layer between thermocouples strips; (5) $10 \mathrm{~mm}$ (thickness) asbestos layer; (6) Guard Heater; (7) $10 \mathrm{~mm}$ (thickness) asbestos layer; (8) $7 \mathrm{~mm}$ (thickness) fiber glass outer insulation layer 


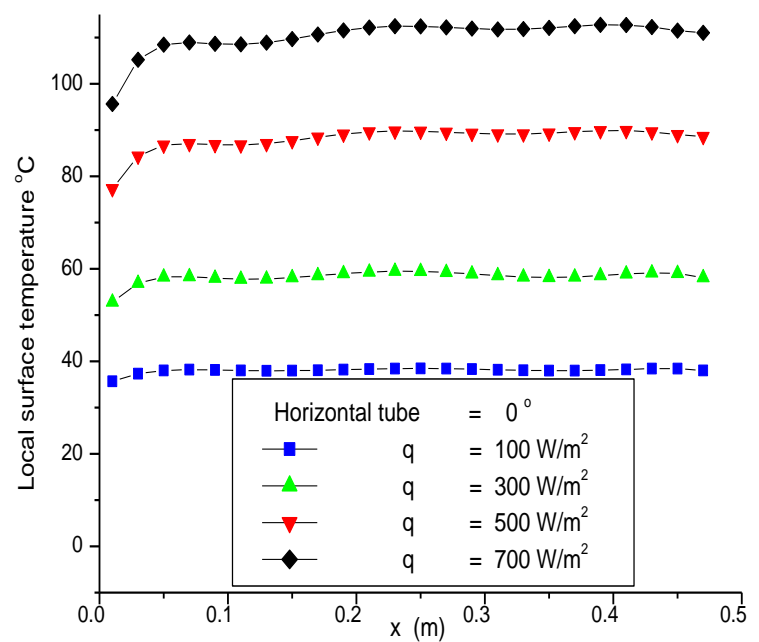

Fig. (3) Variation of local surface temperature along the horizontal tube, for different heat flux and for a constant Reynolds number $\operatorname{Re}_{\mathrm{D}}=\mathbf{8 5 0}$.

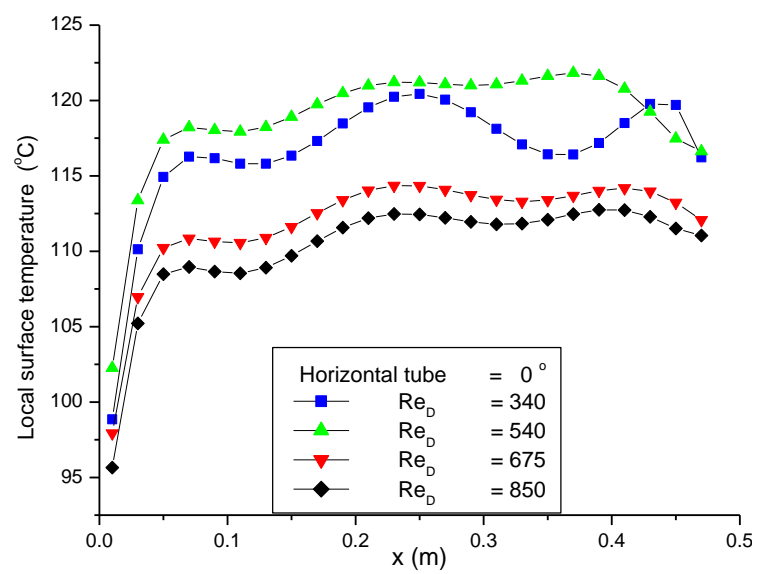

Fig. (4) Variation of local surface temperature along the horizontal tube, for different Reynolds numbers and for constant heat flux $q=700 \mathrm{~W} / \mathrm{m}^{2}$

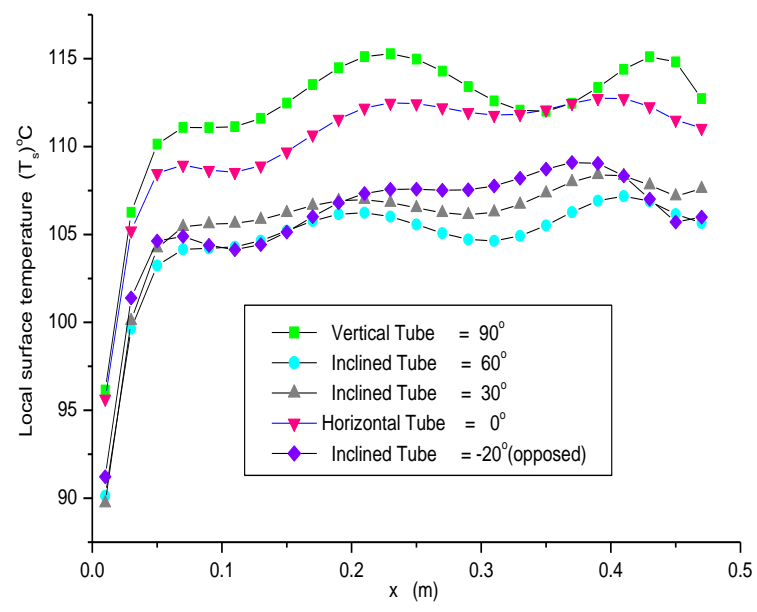

Fig. (5) Effect of tube angle of inclination on the variation of local surface temperature along the tube for Reynolds No. $\operatorname{Re}_{D}=850$ and surface heat flux $q=700 \mathrm{~W} / \mathrm{m}^{2}$.

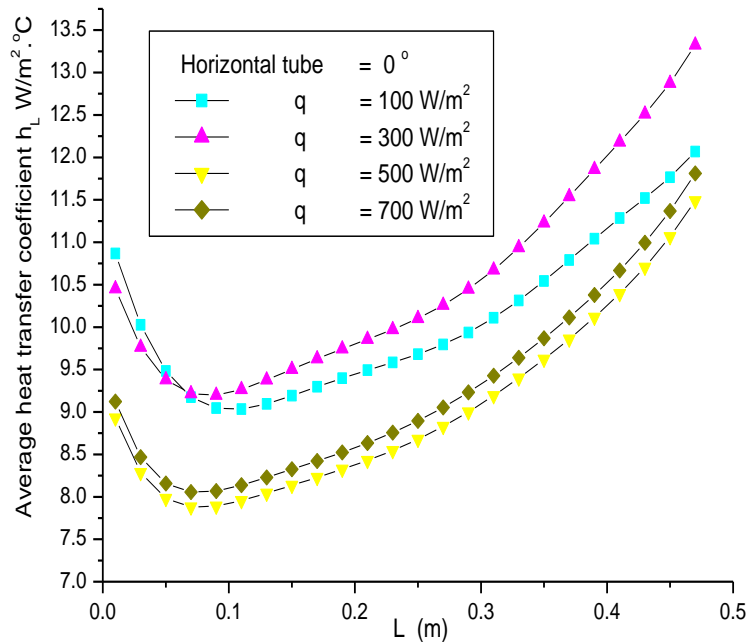

Fig. (6) Variation of average heat transfer coefficient along the tube, for different heat flux and for constant Reynolds number $\mathbf{R e}_{\mathrm{D}}=\mathbf{8 5 0}$.

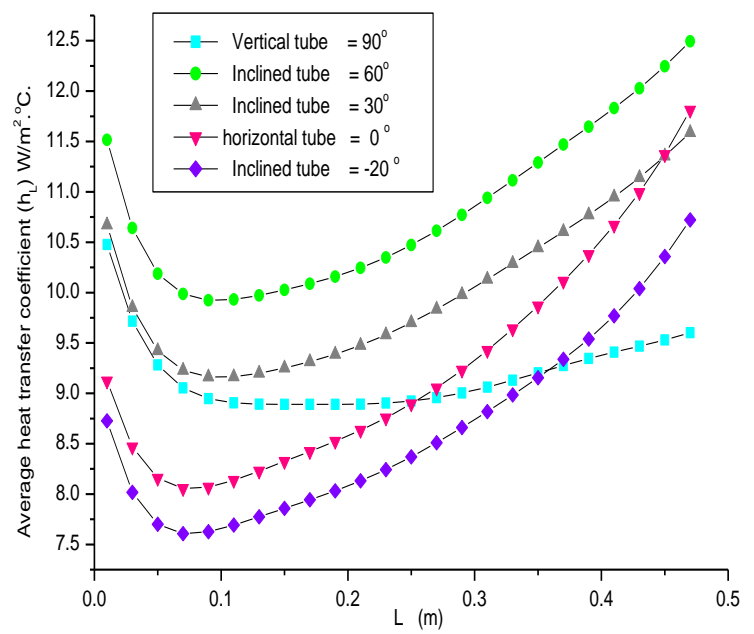

Fig. (7) Effect of tube inclination angle on the variation of average heat transfer coefficient along the tube, for Reynolds No. $\operatorname{Re}_{D}=850$ and surface heat flux $q=700$ $\mathbf{W} / \mathbf{m}^{2}$.

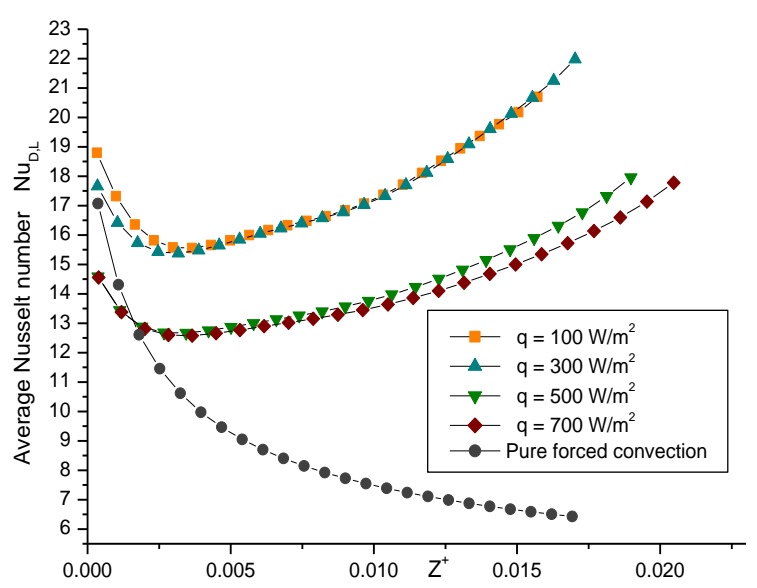

Fig. (8) Variation of average Nusselt number with dimensionless axial distance $\left(Z^{+}\right)$for horizontal tube, for different tube heat flux and for constant Reynolds number $\mathrm{Re}=\mathbf{8 5 0}$. 


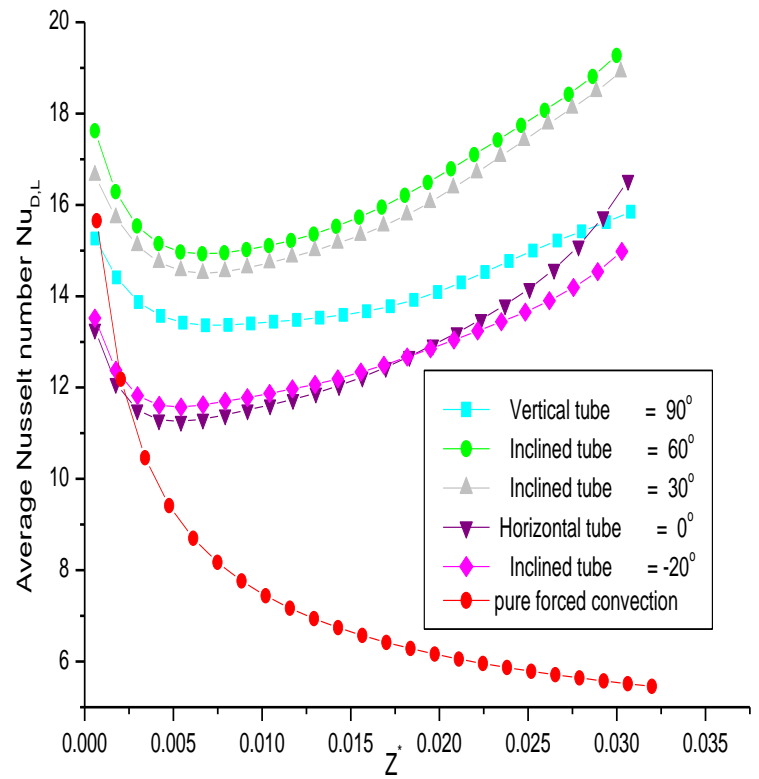

Fig. (9) Effect of tube inclination angle on the average Nusselt number with the dimensionless axial distance, for

Reynolds number $\operatorname{Re}_{\mathrm{D}, \mathrm{L}}=850$ and tube heat flux $\mathrm{q}=700 \mathrm{~W} / \mathrm{m}^{2}$

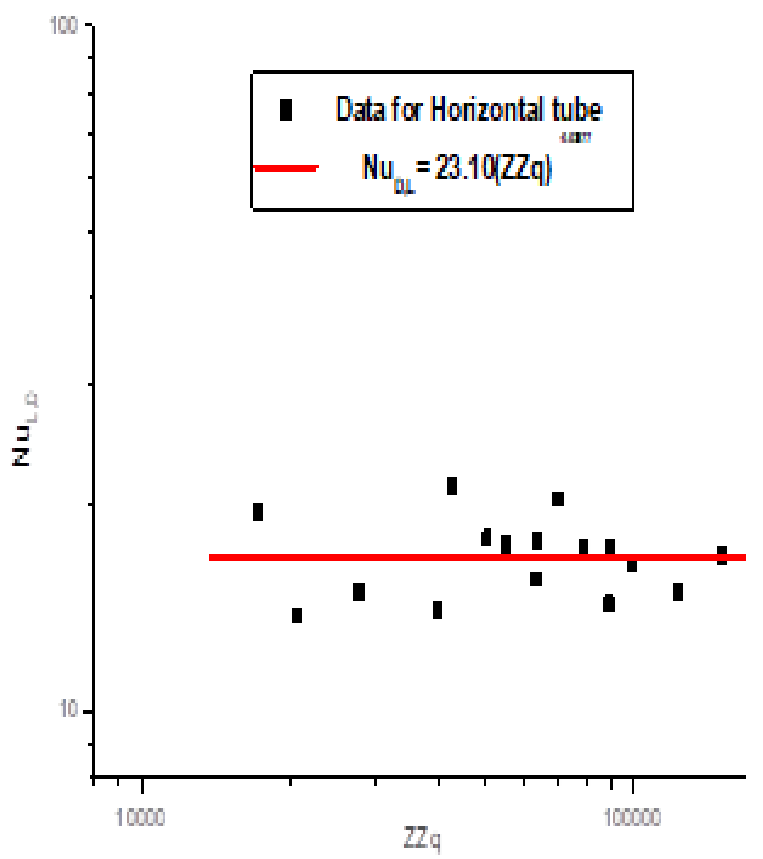

Fig. (10) Correlation of average Nusselt number with $\mathbf{Z Z q}$ based on modified Grashof number for a laminar mixed convection in a horizontal tube.

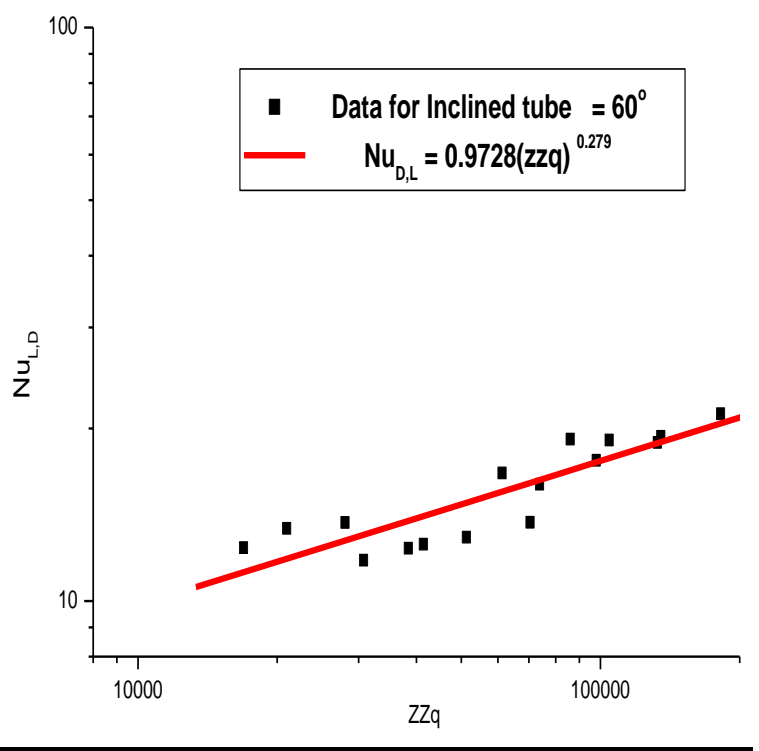

Fig (11) Correlation of average Nusselt number with $\mathrm{ZZq}$ based on modified Grashof number for a laminar mixed convection in an inclined tube $=60^{\circ}$.

Nomenclature

$\mathrm{A}_{\mathrm{s}}$ Tube surface area . $\mathrm{m}^{2}$

$\mathrm{Cp}$ Specific heat at constant pressure. $\mathrm{kJ} / \mathrm{kg} .{ }^{\circ} \mathrm{C}$

D Tube diameter. $\mathrm{m}$

g Gravitational acceleration $\mathrm{m} / \mathrm{sec}^{2}$

$\mathrm{h}_{\mathrm{x}} \quad$ Local heat transfer coefficient. $\mathrm{W} / \mathrm{m}^{2} . \mathrm{K}$

$h_{L} \quad$ Average heat transfer coefficient. $W / \mathrm{m}^{2}$.

I Heater current.Amp.

K Thermal conductivity. W/m.K

$\mathrm{L}$ Axial length of the cylinder. $\mathrm{m}$

$\dot{m}$ Mass flow rate. $\mathrm{Kg} / \mathrm{sec}$.

$\mathrm{Q}_{\mathrm{C}}$ Heat transfer by convection. W

$\mathrm{Q}_{\mathrm{Cd}}$ Heat transfer by conduction. W

$\mathrm{Q}_{\mathrm{t}}$ Total heat input. W

$\mathrm{Q}_{\mathrm{cr}}$ Heat transfer by convetion and radiation. W

$\mathrm{q}_{\mathrm{c}}$ Convetion heat flux.W/m $/ \mathrm{m}^{2}$

$\mathrm{q}_{\mathrm{r}} \quad$ Radiation heat flux. $\mathrm{W} / \mathrm{m}^{2}$

$\mathrm{q}_{\mathrm{cr}}$ Convection - radiation heat flux. W/ $\mathrm{m}^{2}$

$\mathrm{T}_{\mathrm{b}, \mathrm{L}}$ Average bulk air temperature. $\mathrm{C}$

$\mathrm{T}_{\mathrm{f}, \mathrm{x}}$ Local film air temperature.C

$\mathrm{T}_{\mathrm{f}, \mathrm{L}}$ Average film air temperature.C

$\mathrm{T}_{\mathrm{s}, \mathrm{x}}$ Tube local surface temperature.C

$\mathrm{T}_{\mathrm{S}, 1}$ Average tube surface temperature.C

$\mathrm{T}_{\mathrm{b}, \mathrm{x}}$ Local bulk air temperature. $\mathrm{C}$

V Heater voltage. Volt.

$\mathrm{X}$ Local axial distance $\mathrm{m}$ 


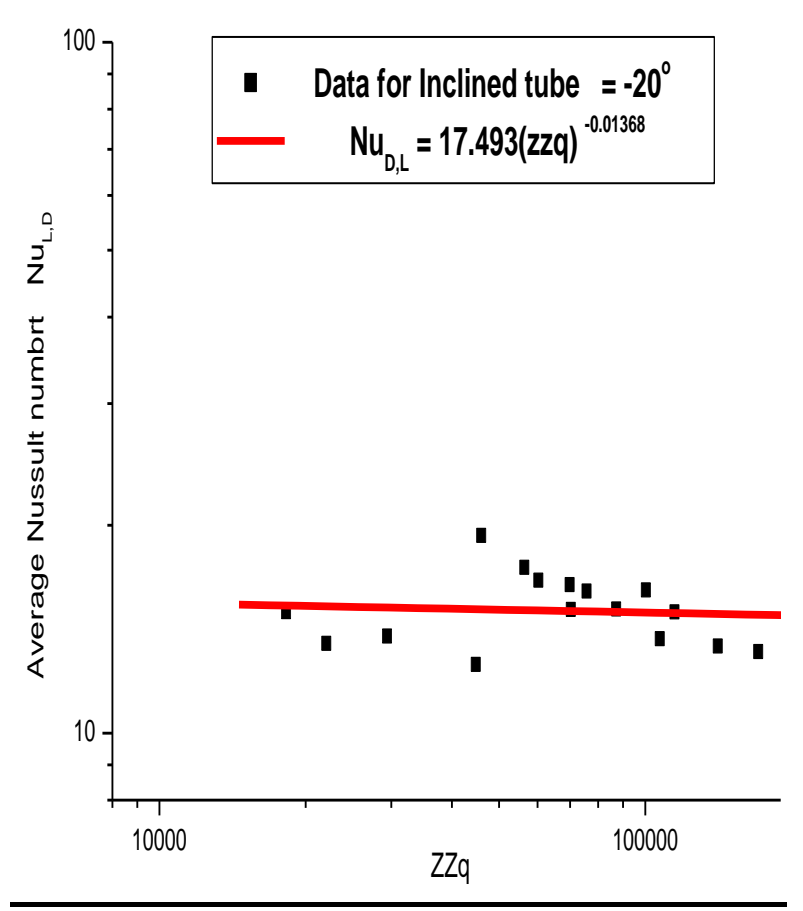

Fig.(12) Correlation of average Nusselt number with $\mathrm{ZZq}$ based on modified Grashof number for a laminar mixed convection in an Inclined tube $=\mathbf{- 2 0}$.

Greek Symbols

$\beta \quad$ Coefficient for volumetric thermal expansion. $\mathrm{K}^{-1}$

$\varepsilon \quad$ Emissivity of surface.

$\mu \quad$ Fluid viscosity. $\mathrm{kg} / \mathrm{m}$.s

$v \quad$ Kinematics viscosity. $\mathrm{m}^{2} / \mathrm{s}$

$\rho \quad$ Density $\mathrm{kg} / \mathrm{m}^{3}$

$\sigma \quad$ Stefan-Boltzmann constant. W/m $\mathrm{m}^{2} \cdot \mathrm{K}^{4}$

$\Theta \quad$ Inclination angle. Degree

Dimensionless group

\begin{tabular}{|c|c|}
\hline \hline Symbol & Definition \\
\hline \hline $\mathrm{F}_{1-2}$ & View factor between the tube walls. \\
\hline \hline $\mathrm{Gr}_{\mathrm{D}, \mathrm{x}}$ & Local Grashof number based on $\mathrm{D}, \frac{\mathrm{g} \beta_{\mathrm{x}}\left(\mathrm{T}_{\mathrm{s}, \mathrm{x}}-\mathrm{T}_{\mathrm{b}, \mathrm{x}}\right) \mathrm{D}^{3}}{v^{2} \mathrm{x}}$. \\
\hline
\end{tabular}

\begin{tabular}{|c|c|}
\hline $\mathrm{Gr}_{\mathrm{D}, \mathrm{L}}$ & Average Grashof number based on $\mathrm{D}, \frac{\mathrm{g} \beta_{\mathrm{L}}\left(\mathrm{T}_{\mathrm{s}, \mathrm{L}}-\mathrm{T}_{\mathrm{b}, \mathrm{L}}\right) \cdot \mathrm{D}^{3}}{v_{\mathrm{L}}^{2}}$ \\
\hline $\mathrm{Ra}_{\mathrm{D}, \mathrm{L}}$ & Average Rayleigh number based on $\mathrm{D}, \mathrm{Gr}_{\mathrm{D}, \mathrm{L}} \operatorname{Pr}_{\mathrm{L}}$ \\
\hline $\mathrm{Ra}_{\mathrm{D}, \mathrm{x}}^{*}$ & Local modified Rayleigh number based on $G r_{D, x}^{*} \operatorname{Pr}_{\mathrm{x}}$ \\
\hline $\mathrm{Ra}_{\mathrm{D}, \mathrm{L}}^{*}$ & $\begin{array}{l}\text { Average modified Rayleigh number based on D } \\
\qquad G r_{D, L}^{*} \operatorname{Pr}_{\mathrm{L}}\end{array}$ \\
\hline $\operatorname{Re}_{\mathrm{D}, \mathrm{x}}$ & Local Reynold number based on $\mathrm{D}, \frac{U . D}{v_{x}}$ \\
\hline $\operatorname{Re}_{\mathrm{D}, \mathrm{L}}$ & Average Reynold number based on $\mathrm{D}, \frac{\mathrm{U} . \mathrm{D}}{\mathrm{v}_{\mathrm{L}}}$ \\
\hline $\mathrm{Z}^{+}$ & Dimensionless axial distance, $\frac{\mathrm{X}}{D \cdot R e_{D, L} \cdot P r_{L}}$ \\
\hline
\end{tabular}

Subscripts

\begin{tabular}{|c||c|}
\hline symbol & definition \\
\hline \hline B & Bulk. \\
\hline C & Convection. \\
\hline Cond & Conduction. \\
\hline Cr & Convection-radiation. \\
\hline D & Based on diameter. \\
\hline f & Film. \\
\hline L & Average. \\
\hline R & Radiation. \\
\hline S & Surface \\
\hline $\mathrm{X}$ & Local. \\
\hline
\end{tabular}

Superscript

\begin{tabular}{|c||c||}
\hline Symbol & Definition \\
\hline+ & - \\
\hline$*$ & Dimensionless. \\
\hline
\end{tabular}

Table (4.1) correlated equations for mixed convection heat transfer to hydrodynamically developed and thermally developing airflow in an inclined circular cylinder

\begin{tabular}{||c||c||c||}
\hline $\begin{array}{c}\text { cylinder inclination } \\
\text { angle }\end{array}$ & Correlation based Rayliegh number & $\begin{array}{c}\text { Correlation based on modified Rayliegh } \\
\text { number }\end{array}$ \\
\hline \hline Vertical $\theta=90^{\circ}$ & $\mathrm{Nu}_{\mathrm{D}, \mathrm{L}}=3.455\left(\mathrm{ZZ}^{+}\right)^{0.157}$ & $\mathrm{Nu}_{\mathrm{D}, \mathrm{L}}=2.429\left(\mathrm{ZZ}_{\mathrm{q}}^{+}\right)^{0.1525}$ \\
\hline \hline Inclined $\boldsymbol{\theta}=\mathbf{6 0}^{\circ}$ & $\mathrm{Nu}_{\mathrm{D}, \mathrm{L}}=1.515\left(\mathrm{ZZ}^{+}\right)^{0.279}$ & $\mathrm{Nu}_{\mathrm{D}, \mathrm{L}}=\mathbf{0 . 9 7 2 8}\left(\mathrm{ZZ}_{\mathrm{q}}^{+}\right)^{0.2515}$ \\
\hline \hline Inclined $\boldsymbol{\theta}=\mathbf{3 0}^{\circ}$ & $\mathrm{Nu}_{\mathrm{D}, \mathrm{L}}=4.811\left(\mathrm{ZZ}^{+}\right)^{\mathbf{0 . 1 4 3 6}}$ & $\mathrm{Nu}_{\mathrm{D}, \mathrm{L}}=3.191\left(\mathrm{ZZ}_{\mathrm{q}}^{+}\right)^{0.145}$ \\
\hline \hline Horizontal $\theta=\mathbf{0}^{\circ}$ & $\mathrm{Nu}_{\mathrm{D}, \mathrm{L}}=17.317\left(\mathrm{ZZ}^{+}\right)^{-0.00281}$ & $\mathrm{Nu}_{\mathrm{D}, \mathrm{L}}=23.10\left(\mathrm{ZZ}_{\mathrm{q}}^{+}\right)^{-0.03877}$ \\
\hline \hline Inclined $\theta=-20^{\circ}$ & $\mathrm{Nu}_{\mathrm{D}, \mathrm{L}}=21.6\left(\mathrm{ZZ}^{+}\right)^{-0.04297}$ & $\mathrm{Nu}_{\mathrm{D}, \mathrm{L}}=17.493\left(\mathrm{ZZ}_{\mathrm{q}}^{+}\right)^{-0.01365}$ \\
\hline
\end{tabular}


Table (4.2) the percentage reduction and improvement in the mixed convection heat transfer for the range of cylinder inclination angle tested related to horizontal cylinder.

\begin{tabular}{|c|c||c||}
\hline $\begin{array}{c}\text { Cylinder } \\
\text { inclination angle }\end{array}$ & Minimum $\mathrm{zz}_{\mathrm{q}}^{+}$value & Maximum $\mathrm{zz}_{\mathrm{q}}^{+}$value \\
\hline \hline $\boldsymbol{\theta}=-\mathbf{2 0}{ }^{\circ}$ & $-2.88 \%$ & $+2.8 \%$ \\
\hline $\boldsymbol{\theta}=\mathbf{0}^{\circ}$ & 0 & $\mathbf{0}$ \\
\hline \hline $\boldsymbol{\theta}=\mathbf{3 0}^{\mathbf{0}}$ & $-12.7 \%$ & $+30.15 \%$ \\
\hline \hline $\boldsymbol{\theta}=\mathbf{6 0}^{\circ}$ & $-25.38 \%$ & $+45.6 \%$ \\
\hline \hline $\boldsymbol{\theta}=\mathbf{9 0}^{\circ}$ & $-30.1 \%$ & $+8.6 \%$ \\
\hline
\end{tabular}

\section{REFERENCES}

[1] Raisee M. and Shahraeeni M. "Numerical Simulation of Laminar Mixed Convection of Air Flow through Uniformly Heated Vertical Tubes". In ASME/JSME 2007 Thermal Engineering Summer Heat Transfer Conference collocated with the ASME 2007 inter PACK Conference, PP. 1055-1061, American Society of Mechanical Engineers, (2007).

[2] Ozsunar A., Baskaya S. and Sivrioglu M., "Experimental Investigation of Mixed Convection Heat Transfer in a Horizontal and Inclined Rectangular Channel”. Heat and Mass transfer, Vol.38, No 3, PP.271-278, (2002).

[3] Mohammed H. and Yusaf T. "Heat Transfer by Mixed Convection Opposing Laminar Flow from the Inside Surface of Uniformly Heated Inclined Circular Tube".In ASME 8th Biennial Conference on Engineering Systems Design and Analysis (pp.165-175). American Society of Mechanical Engineers, (2006).

[4] Mohammed H.A. and Salman Y.K., "Experimental Investigation of Mixed Convection Heat Transfer for
Thermally Developing Flow in a Horizontal Circular Cylinder", Applied Thermal Engineering, Vol.27, No 89, PP.1522-1533, (2007)

[5] Dogan.A., Sivrioglu M. and Baskaya S., "Investigation of Mixed Convection Heat Transfer in a Horizontal Channel with Discrete Heat Sources at the Top and at the Bottom", International Journal of Heat and Mass Transfer, Vol.49, No 15-16, PP.2652-2662, (2006).

[6] Mare'T., Voicu I. and Miriel J., "Numerical and Experimental Visualization of Reverse Flow in an Inclined Isothermal Tube", Experimental Thermal and Fluid Science, Vol.30, No 1, PP.9-15, (2005).

[7] Holman J. P. "Heat transfer",10th edition, McGraw-Hill Series in Mechanical Engineering,(2010).

[8] Holman J. P. (Jack Philip) "Experimental methods for engineers", 8th ed. McGraw-Hill Series in Mechanical Engineering,(2011).

[9] Kays, W. M. and Crawford, M. E.' Convective Heat and Mass Transfer', third edition,McGraw - Hill,(1993) 